\title{
The effect of discretization of hydrologic response units on the performance of SWAT model in simulating flow and evapotranspiration
}

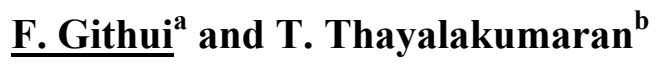 \\ Future Farming Systems Research Division, Department of Primary Industries \\ ${ }^{a}$ Ferguson Road, Tatura VIC 3616 \\ ${ }^{b} 1301$ Hazeldean Road, Ellinbank VIC 3616 \\ Email: faith.githui@dpi.vic.gov.au
}

\begin{abstract}
The approach to hydrological modelling has changed over time in the face of a changing climate, land use and development and management of water resources, putting more emphasis on quantification of water balance components within the catchment than flow at catchment/sub-catchment levels. This has created a need to have an almost explicit representation of landscape heterogeneity, which can be handled by distributed hydrological models. A disadvantage of these distributed models is that they are highly parameterized and thus, attempts are made to simplify the model through lumping of some parameters and losing some of the fine details in the landscape heterogeneity. Various studies have investigated the effects of aggregation of model input parameters on model outputs. These effects vary with the chosen spatial scale (model input and calibration data), key processes simulated in the model and the types of model outputs considered.
\end{abstract}

In this study, we investigate at a much finer scale, the impact of the number and size of hydrologic response units (HRUs) on flow and evapotranspiration. We applied the Soil and Water Assessment Tool (SWAT), a semi-distributed hydrological model, to an irrigated catchment in south east Australia. Three models were compared with different number of HRUs and parameters. These are i) 11-HRU, ii) 98-HRU, and iii) 11HRUCrV (i.e. model with 98-HRU parameters applied to the 11-HRU model). This comparison was important because the number of remotely sensed actual evapotranspiration (ETrs) data points for calibration of the SWAT model depended on the total number of HRUs in the catchment, in addition to flow. After a one year warm-up, the SWAT model was calibrated using flow and ETrs.

In general, the model catchment and within-catchment outputs (flow and evapotranspiartion) exhibited different sensitivities to the scale of calibration i.e coarse versus fine HRU representation. Monthly flow was calibrated with a reasonable accuracy. Catchment ET was not affected by the number of HRUs used in the model. This is because in the 11-HRU the dominant soil and land uses were used which together covered more than $70 \%$ of the catchment. In addition, the simulated catchment ET was not affected by the transfer of parameters between the models. On the other hand, flow seemed to be influenced both by the number of HRUs (mainly due to land use and irrigation management) and model parameterization. The 11-HRU model was seen to perform better than the 98-HRU in simulating catchment flow and ET. However, withincatchment water fluxes were found to be variable within a model as well as between the models, and so a more detailed catchment discretization would provide a better quantification of the water balance components. Greater variability of evapotranspiration observed across land use than the soil type suggests that fine discretization of land use data than of the soil type could improve within catchment water flux results in this catchment. The different sensitivities of flow and evapotranspiration (daily and monthly) to the scale of calibration can provide a guide as to which model output has a higher priority according to the objectives of the study.

Keywords: $\quad$ Hydrologic response units, SWAT, model spatial scale, remotely sensed evapotranspiration 
Githuia and Thayalakumaran, The effect of discretization of hydrologic response units on the performance of SWAT model in simulating flow and evapotranspiration

\section{INTRODUCTION}

The need for hydrological modelling has changed over time in the face of a changing climate, land use and development and management of water resources. As a consequence, emphasis has gradually shifted from making predictions of flow at catchment/sub-catchment levels towards quantification of water balance components within the catchment. This has created a need to have an almost explicit representation of landscape heterogeneity, which is handled by distributed hydrological models. These distributed models are highly parameterized making it difficult to find a representative parameter set for the catchment (Beven, 2001; Vache and McDonnell, 2006). Thus, attempts are made to simplify the model through lumping of some parameters and losing some of the fine details in the landscape heterogeneity. Often, parameter sets obtained in this way have failed when extrapolated to catchments in different places and with varying scales.

In order to capture the heterogeneity within the catchment, input data that are spatially distributed such as land use, soil, topography and weather variables are required in the models. In addition, moving away from the traditional use of flow at catchment/sub-catchment as the only calibration data, use of the now more available remotely-sensed data such as evapotranspiration is becoming more common (Immerzeel and Droogers, 2008; Jhorar et al., 2009). Spatially distributed calibration data helps to constrain and identify model parameters that vary with the given landscape heterogeneity, providing a more representative parameter set across the catchment (Githui and Thayalakumaran, 2011).

Various studies have investigated the effects of aggregation of model input parameters on model outputs. These effects vary with the chosen spatial and temporal scale (model input and calibration data), key processes simulated in the model and the types of model outputs considered. For example, Jha et al, (2004) and Muleta et al, (2007) showed that streamflow was insensitive to watershed subdivision. Kumar and Merwade (2009) found that, unlike the daily streamflow, the overall monthly and annual streamflow output may not be affected by watershed subdivision. While many of these studies have focussed on the sensitivity of streamflow, few studies have analysed the effects of spatial scale on within-catchment fluxes.

In this study we used the Soil and Water Assessment Tool (SWAT), calibrated using remotely sensed evapotranspiration (ETrs) and flow data, in an irrigated catchment in southeast Australia. To investigate the impact of number and size of hydrologic response units (HRU) on flow and evapotranspiration, model results were analysed at the catchment and HRU scales. HRUs are homogenous units with unique land use/cover and soil attributes.

\section{STUDY AREA}

The Toolamba drainage catchment covers an area of about 3012 ha within the Shepparton irrigation region, southeast Australia and the drainage network outfalls into the Goulburn River. It has a flat topography and is characterized mainly by sandy and loam soils covering about $47 \%$ and $28 \%$ of the catchment area respectively (Figure 2(a)). About half of the catchment was under irrigation for the seasons 2008/2009 and 2009/2010. The rainfall, maximum and minimum temperatures, and irrigation water use are shown in Figure 1. The land use (2008/2009) and soil types are shown in Figure 2.

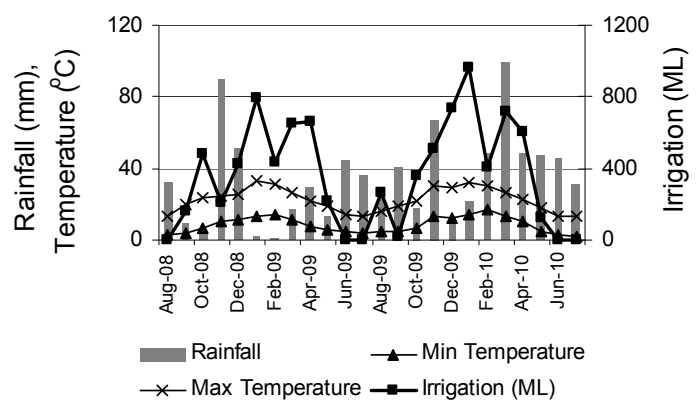

Figure 1: Rainfall, maximum and minimum temperatures, and irrigation water use 

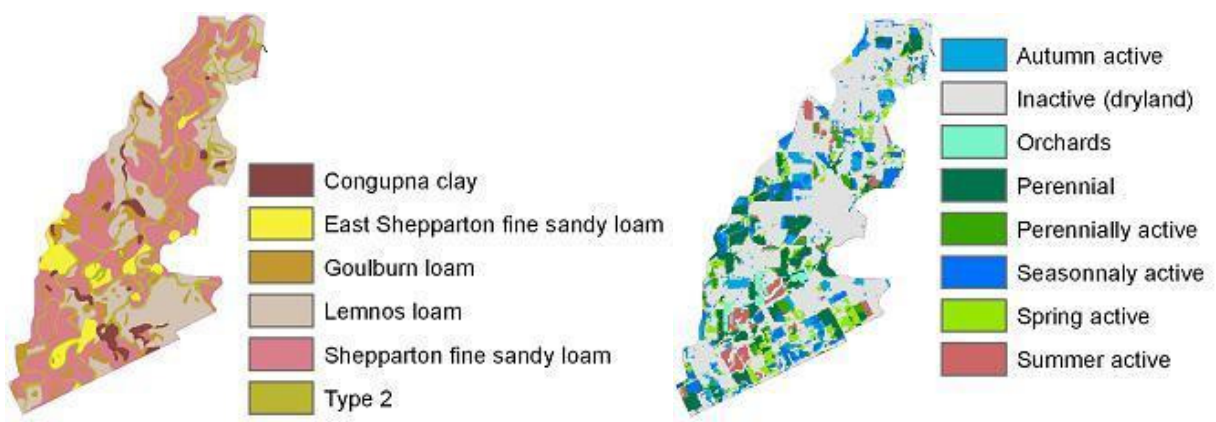

Figure 2: (a) soil, (b) land use (main land use is irrigated pasture - perennials and annuals)

\section{METHODOLOGY}

\subsection{Description of the SWAT model}

SWAT is semi-distributed hydrological model (Arnold et al., 1998) and computes the water balance as given in equation (1).

$$
S W_{t}=S W_{0}+\sum_{i=1}^{t}\left(R+I r r-Q_{\text {surf }}-E_{a}-w_{\text {seep }}-Q_{g w}\right)_{i}
$$

where on day $\mathrm{i}, \mathrm{SWt}$ is the final soil water content $(\mathrm{mm}), \mathrm{SW}_{0}$ is the initial soil water content $(\mathrm{mm}), \mathrm{t}$ is the time (days), $R$ is the amount of precipitation $(\mathrm{mm})$, Irr is the amount of irrigation $(\mathrm{mm}), \mathrm{Q}_{\text {surf }}$ is the amount of surface runoff $(\mathrm{mm}), \mathrm{Ea}$ is the amount of evapotranspiration $(\mathrm{mm}), \mathrm{w}_{\text {seep }}$ is the amount of water percolating to the shallow aquifer $(\mathrm{mm})$, and $\mathrm{Q}_{\mathrm{gw}}$ is the amount of return flow $(\mathrm{mm})$. Inputs into the SWAT model include rainfall, irrigation, maximum and minimum temperature, land cover, soil attributes and elevation. The catchment is subdivided into sub-basins that are spatially related to one another, and then further into hydrologic response units (HRUs) which are homogenous units with unique land use/cover and soil attributes. This accounts for the complexity of the landscape within the sub-basins. More details about the SWAT model can be found in Neitsch et al., (2005).

\subsection{Data}

Data used in SWAT included rainfall, temperature (minimum and maximum), daily flow data Penman Monteith potential evapotranspiration (PET), digital elevation model (20m resolution), soil hydraulic properties (Brijesh and Wang, 2005), remotely sensed actual evapotranspiration, land cover data and irrigation water use. Brief descriptions of irrigation water use and the remotely sensed evapotranspiration data are given below.

\section{Irrigation water use}

The irrigation schedule for each irrigated HRU was generated from four sources of data: the total area under irrigation in a given season (i.e. spring, summer and autumn), an average application rate of $0.5 \mathrm{ML} / \mathrm{ha}$, typically applied in an irrigation event, the annual water delivery to some parts of the study area and the daily irrigation water use measured at Goulburn Murray irrigation outlets on the irrigation supply channel. The annual water use was disaggregated to daily in proportion to the daily measured water use to give the total daily water volume. For a given season (i.e. spring, summer and autumn), the irrigation schedule at the HRU scale was obtained by first accumulating the total daily water use until it at least equalled the monthly water use calculated as the catchment area under irrigation multiplied by the assumed average application rate of $0.5 \mathrm{ML} / \mathrm{ha}$. However, if the accumulated amount of water was insufficient to irrigate the area with a rate of $0.5 \mathrm{ML} / \mathrm{ha}$ by the end of the given season, the accumulation continued for a few days into the next season.

\section{Remotely sensed evapotranspiration (ETrs)}

A total of ten ETrs grid layers were used in extracting HRU averaged actual ETrs. Each grid represented an instantaneous ETrs estimate (ETrs-inst) and the corresponding reference ET (ETref) was also given. The reference (tall crop reference) was calculated following the FAO56 method, using weather data for the time closest to image acquisition time. The ETrs-inst was converted to a daily ET value (ETrs day) by multiplying the ET fraction (i.e. ETrs inst/ETref) with the daily potential ET (PETday) obtained from the weather station, with the assumption that the ET fraction would be constant throughout the day. 
ETrs_day $=\frac{\text { ETrs_inst }}{\text { ETref }} *$ PETday

\subsection{Model set up and calibration}

Using the data described above, the catchment was delineated into two subbasins. Two models were set up, one with 11 HRUs and another with 98 HRUs. In the 11-HRU model, only two dominant soil types were considered and land uses that occupied less than $5 \%$ in area were aggregated with the dominant ones. In the 98-HRU model, all soil types and land uses as shown in Figure 2 were used, thus representing the actual situation as would be observed in the catchment. The average HRU area in the 11-HRU model was about 10 times larger than that in the 98-HRU model.

\section{Model calibration}

With a one-year warm-up period (2007), the model was calibrated using daily drain flow at the catchment outlet and the day ETrs for each of the HRUs in the 2008/2009 season. A total of 55 and 490 ETrs data points for the 11-HRU and 98-HRU models respectively (5 grids * number of HRUs) were extracted. Parameters included in the calibration were i) the soil evaporation compensation factor that modifies the depth distribution used to meet the soil evaporative demand (ESCO), ii) the curve number $(\mathrm{CN})$, iii) the surface runoff lag coefficient that lags a portion of the surface runoff release to the main channel. (SURLAG), (details in Neitsch et al., 2005) and, iv) the irrigation runoff coefficient, represented as a fraction of the irrigation water applied. ESCO and SURLAG were varied at the catchment level while CN was varied by HRU type. Groundwater parameters were not calibrated because base flow was not observed during this period.

The parameter estimation tool PEST (Doherty, 2005), was used for calibration. Using a multiple search which includes random sampling, PEST runs from different starting locations in parameter space to find the global minimum of the objective function in which there may be many local minima (Skahill and Doherty, 2006; Gallagher and Doherty, 2007). PEST uses a non-linear estimation technique, the Gauss-MarquardtLevenberg method and optimizes the fit between observations and model output using weighted least squares. The objective function is given by:

$$
O F=\sum_{i=1}^{n}\left(w_{i} r_{i}\right)^{2}
$$

where $n, w_{i}$ and $r_{i}$ represent the number of observations, the $i^{\text {th }}$ weight of the observations and residuals (observed minus modelled data) respectively. The weights were assigned in inverse proportion to measurement standard deviations while ensuring that the contribution to the objective function of one observation type did not dominate the other (Doherty, 2005).

The models 11-HRU and 98-HRU were calibrated separately and then the 98-HRU model parameters were applied to the 11-HRU (hereafter referred to as the 11-HRUCrV model). This cross-simulation was performed to evaluate the differences in the two models' performance due to calibration. Calibration can mask some differences that may occur as a result of HRU number and size. Statistics used in the comparison of model results were the coefficient of determination $\left(\mathrm{R}^{2}\right)$, Nash and Sutcliffe efficiency (NSE) and significance test (ANOVA).

\section{RESULTS AND DISCUSSION}

\subsection{Analysis of catchment outputs}

The calibrated 11-HRU and 98-HRU models yielded different parameters sets however, all within the expected range. Results presented in Table 1 show that monthly flow was calibrated with a reasonable accuracy in 11-HRU and 98-HRU models, but not in the 11-HRUCrV model where the 98-HRU model parameters were applied to the 11-HRU model. Land use in the 98-HRU model which was not present in the 11-HRUCrV model, generated markedly different flows that could have caused the differences observed. Note that the 11-HRUCrV model was not calibrated against flow or ETrs.

The daily flow for all the models was poorly simulated with a Nash Sutcliffe efficiency, NSE $<0$ (results not shown). This is because for most of the year, the flow is mainly generated from irrigation runoff which is 
calibrated using an irrigation runoff coefficient that is varied month by month. The assumed irrigation scheduling in the model may not conform to the actual irrigation management. Furthermore, it is assumed in the model that irrigation is applied on the same day to those HRUs being irrigated in that month. This has implications for the timing of the irrigation runoff peaks and consequently poor simulation of daily flow.

Table 1: Model performance in simulating monthly drain flow and day-evapotranspiration (NSE - Nash Sutcliffe efficiency, $\mathrm{R}^{2}$ - coefficient of determination)

\begin{tabular}{lcc}
\hline Models & $\begin{array}{c}\text { Monthly flow } \\
\text { NSE }\end{array}$ & $\begin{array}{c}\text { Day-actual ET } \\
\mathbf{R}^{\mathbf{2}}\end{array}$ \\
\hline 11-HRU & 0.97 & 0.40 \\
98-HRU & 0.78 & 0.36 \\
11-HRUCrV & 0.34 & 0.32 \\
\hline
\end{tabular}

Overall, there was lack of a good fit for the modelled day-evapotranspiration (Table 1). Similar $\mathrm{R}^{2}$ values obtained for the 11-HRU and the 98-HRU models indicate the variation of ETrs within a given HRU did not seem to affect the efficiency of the simulated ET. It was expected that this would have had an impact due to the averaging of non-uniform ETrs pixels within a HRU. It was found that the day-of-year (DOY) and type of land use had a great influence on simulating ET. The use of a one-day per month ETrs for calibration may have contributed to the poor simulation. This is because the modelled ET would depend on the simulation of pasture growth by the model which can vary considerably from day to day depending on the timing of irrigation, planting and harvesting times, grazing, rainfall and more generally farmer-dependent irrigation management practices that may not be captured adequately in the model. In order to represent more accurately the seasonal pattern of plant growth, it may be more appropriate to use monthly ET/cumulative ET data for calibration instead of a one-day ET value per month as has been used here.

Table 2: p-values showing the differences in catchment simulated flow and evapotranspiration between the three models; 11-HRU, 98-HRU and 11-

\begin{tabular}{|c|c|c|c|c|}
\hline \multirow[b]{3}{*}{ Models } & \multicolumn{4}{|c|}{ ANOVA p-Values } \\
\hline & \multicolumn{2}{|c|}{ Daily } & \multicolumn{2}{|c|}{ Monthly } \\
\hline & Flow & ET & Flow & ET \\
\hline 11-HRU vs 98-HRU & 0.09 & 0.02 & 0.16 & 0.60 \\
\hline 11-HRU vs 11-HRUCrV & 0.01 & 0.02 & 0.02 & 0.57 \\
\hline 11-HRUCrV vs 98-HRU & 0.02 & 0.84 & 0.22 & 0.96 \\
\hline
\end{tabular}

Comparing the two models (Table 1), the coarser 11-HRU model seems to perform slightly better than the more detailed 98-HRU model for both monthly flow and day-evapotranspiration. However, ANOVA analysis $(a l p h a=0.05)$ showed insignificant differences $(p=0.09)$ for flow while the differences were significant $(p=$ 0.02 ) for evapotranspiration (Table 2). At a monthly scale, simulated catchment flow and ET showed no significant differences between the two models (Table 2 and Figure 3 ).
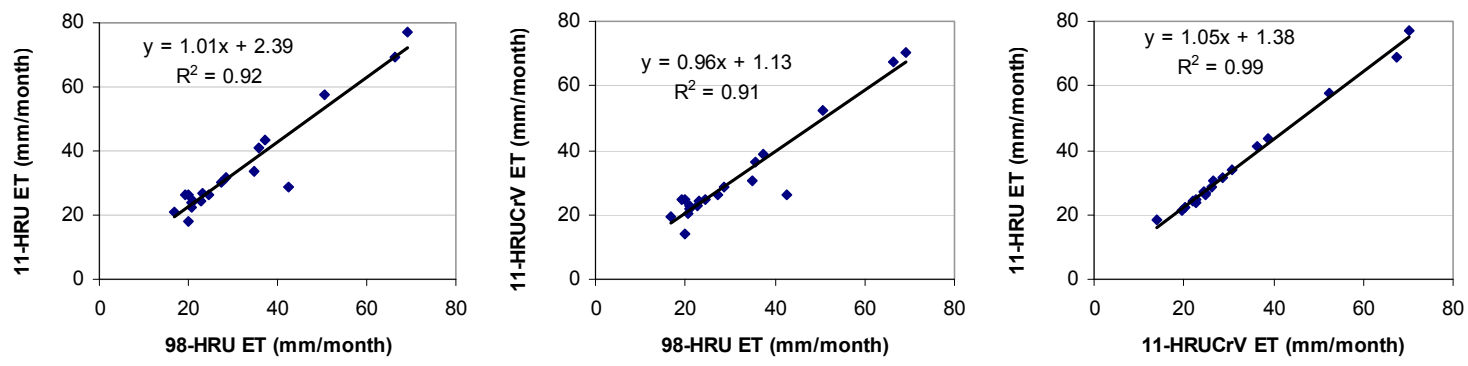

Figure 3: Comparison of catchment simulated monthly evapotranspiration for three models (11-HRU, 98HRU and 11-HRUCrV)

In the 11-HRUCrV model, (i.e. parameters calibrated for the 98-HRU model applied to the 11-HRU model), simulated daily flows were different from those in the other two models while monthly flow showed good agreement (Table 2). In contrast, 11-HRUCrV simulated daily ET compared well with the 98-HRU and not 
with the 11-HRU model. This suggests that the extra land use/soil combinations present in the 98-HRU model do not significantly affect the catchment ET since these two models had the same parameters for the same land use/soil combinations. Also, the dominant land use and soils (which make up the 11-HRU model) covered more than $70 \%$ of the catchment in the 98 -HRU model. Monthly simulated ET for the11-HRUCrV model compared well with both 11-HRU and 98-HRU models (Figure 3).

\subsection{Analysis of HRU output}

Comparisons made in the water balance components, namely ET and water yield at the HRU level, showed that ET was least affected while water yield exhibited marked differences (Table 3). Within a model ET exhibited greater variability across land use than across soil type. It should be noted that the soil parameters were kept at the values across all models. Water yield is the sum of the surface runoff, lateral flow and groundwater. However in this catchment base flow was negligible and the only differences in water yield would be attributed to the partition between recharge and surface runoff.

Table 3: $\mathrm{R}^{2}$ values for comparisons of annual ET and water yield between the three models for similar HRUs (calibration period only)

\begin{tabular}{lcc}
\hline Models & ET & Water yield \\
\hline 11-HRU vs 98-HRU & 0.91 & 0.12 \\
11-HRU vs 11-HRUCrV & 0.97 & 0.31 \\
11-HRUCrV vs 98-HRU & 0.98 & 0.32 \\
\hline
\end{tabular}

The poor correlation of water yield between the models was influenced by the smoothed-out land cover and soils responsible for generating higher flows such as bare land/paths which were not considered in the 11HRU model. Furthermore, the redistribution of irrigation water use affected the HRU water balance through lumping of land use that re-adjusted the area under irrigation. Surface runoff is generated at the HRU level and so altering the distribution of HRU characteristics such as land use and soils through lumping can have an impact on the simulated runoff and consequently flow. Changing only the HRU area without lumping is not expected to affect flow since runoff is based on the curve number and irrigation runoff fraction which are not dependent on area.

\section{SUMMARY}

In this study we investigated the effect on model outputs (catchment and within-catchment) of aggregating land use and soil type. Altering the distribution of HRU characteristics such as land use and soils through lumping can have an impact on the simulated runoff and consequently flow. The results showed that the simulation of catchment ET was not affected by the number of HRUs used in the model. This is because in the 11-HRU model the dominant soil and land uses were used which together covered more than $70 \%$ of the catchment. ET was seen to be influenced more by land use than soil type in this catchment. In addition, the simulated catchment ET was not affected by the transfer of parameters between the models. On the other hand, flow seemed to be influenced both by the number of HRUs (mainly through aggregation of irrigated land use which redistributes the amount of irrigation water applied) and model parameterization.

The 11-HRU model was seen to perform better than the 98-HRU in simulating catchment flow and ET. This suggests that for catchment-averaged outputs, fine discretization of the catchment may not provide better results and this would save time in model run times as well as reduce the number of parameters for calibration. However, differences in within-catchment water fluxes, and the greater variability of evapotranspiration observed across land use than the soil types suggests that fine discretization of land use than soil type could improve within-catchment water flux results. On the other hand, changing only the HRU area without lumping is not expected to affect catchment flow since runoff is based on the curve number and irrigation runoff fraction which are not directly dependent on area. In general, the daily and monthly model outputs (flow and evapotranspiartion) exhibited different sensitivities to the spatial scale of calibration. These sensitivities can provide a guide as to which model output has a higher priority according to the objectives of the study.

Future work aims to obtain higher temporal resolution of ETrs for calibration of the model. It is also envisaged that further analysis will be done on model simplification at different levels with regard to land use and soil combinations that would have insignificant differences in the HRU water balance as well as inclusion of errors in the input and calibration data. 
Githuia and Thayalakumaran, The effect of discretization of hydrologic response units on the performance of SWAT model in simulating flow and evapotranspiration

\section{ACKNOWLEDGEMENT}

This work is funded by the Department of Primary Industries, Victoria, Australia. We thank the Spatial Sciences Group Department of Primary Industries, Victoria and Goulburn-Murray Water for providing the data.

\section{REFERENCES}

Arnold J.G., R., Srinivasan, R.S., Muttiah, and J.R. Williams (1998). Large area hydrologic modelling and assessment Part 1: Model development. Journal of American Water Resources Association 34(1): 73-89.

Beven, K. (2001). How far can we go in distributed hydrological modelling?. Hydrology Earth Systems Science, 5, 1-12.

Brijesh M. and Q.J. Wang (2005). Soil Hydraulic Properties of the Shepparton Irrigation Region. Department of Primary Industries and Department of Sustainability and Environment, ISBN 1741469619.

Doherty J. (2005). PEST - Model independent parameter estimation 5th edition. Watermark Numerical Computing. Australia.

Githui F. and T. Thayalakumaran (2011). Calibration of SWAT model using remotely-sensed evapotranspiration for an irrigated catchment in southeastern Australia. $34^{\text {th }}$ IAHR Biennial Congress 26 Brisbane, Australia in June-1 July 2011.

Gallagher M. and J. Doherty (2007). Parameter estimation and uncertainty analysis for a watershed model. Environmental Modelling and Software 22: 1000-1020.

Immerzeel W.W. and P. Droogers (2008). Calibration of a distributed hydrological model based on satellite evapotranspiration, Journal of Hydrology 349: 411-424.

Jha M., P.W. Gassman, S. Secchi, R. Gu, and J. Arnold (2004). Effects of watershed subdivision on SWAT flow, sediments and nutrient predictions. Journal of American Water Resources Association 40(3):811825.

Jhorar R.K., A., Smit, W.G.M., Bastiaanssen, and C.W.J.,Roest (2009). Calibration of a Distributed Irrigation Water Management Model Using Remotely Sensed Evapotranspiration Rates and Groundwater Head. Irrigation and Drainage. DOI: 10.1002/ird.541.

Kumar S., and V. Merwade (2009). Impact of watershed subdivision and soil data resolution on swat model calibration and parameter uncertainty. Journal of the American Water Resources Association (JAWRA) 45(5):1179-1196.

Muleta, M.K., J.W. Nicklow, and E.G. Bekele (2007). Sensitivity of a distributed watershed simulation to spatial scale. Journal of Hydrologic Engineering 12(2):163-172.

Neitsch S.L., J.G., Arnold, J.R., Kiniry and J.R. Williams (2005). Soil and Water Assessment Tool. Theoretical Documentation Version 2005. Grassland, Soil And Water Research Laboratory Agricultural Research Service, Texas 76502, Blackland Research Center, Texas Agricultural Experiment Station, Texas 76502 USA.

Skahill B.E., and J. Doherty (2006). Efficient accommodation of local minima in watershed model calibration. Journal of Hydrology 329: 122-139.

Vache, K.B., and J.J. McDonnell (2006). A process based rejectionist framework for evaluating catchment runoff model structure. Water Resources Research, 42, W02409. 